\title{
5 Bibliographischer Nachweis der Abbildungen
}

Abb. 1: Holter, Alfred: Dreissig Jahre Gallspach. Wels: Leitner 1956, zweites Bild nach S. 96.

Abb. 2: Karwald, Friedrich Adolf: Das enthüllte Geheimnis von Gallspach. Mit 600.000 Volt gegen den Tod. Unparteiische Darstellung der Falles Zeileis. Wien: Amonesta 1930, S. 21.

Abb. 3: Holter, Alfred: Dreissig Jahre Gallspach. Wels: Leitner 1956, neben S. 80 .

Abb. 4: Kramer, Philipp Walburg: Der Heilmagnetismus. Seine Theorie, seine praktische Anwendung und seine Erfolge. Mit einem Vorwort von Gottfried Buchner. Mit Bildern, gestellt von Magnetopath Fr. J. Wetterer. Und mit einem Anhang: Der magnetische Schlaf als Mittel zur Entwicklung der Gabe des Hellsehens von Andrew Jackson Davis. Lorch: Renatus 1931, ohne Seite.

Abb. 5: Grenzgänger, Wunderheiler, Pflastersteine. Die Geschichte der Gleimstraße in Berlin, hrsg. v. Kulturamt Prenzlauer Berg, Prenzlauer-BergMuseum für Heimatgeschichte und Stadtkultur. Berlin: Basisdruck 1998, S. 195.

Abb. 6: Ebd., S. 180.

Abb. 7: Linse, Ulrich: Geisterseher und Wunderwirker. Heilsuche im Industriezeitalter. Frankfurt a. M.: Fischer 1996, S. 142-143.

Abb. 8: Grosche, Heinz: Die „sensationellen Krankenheilungen“ des Homburger Wunderdoktors. In: Frankfurter Allgemeine Zeitung, Nr. 87, 14.04.1988, S. 40. 